\title{
MULTI-DRUG RESISTANT UROPATHOGENS ISOLATED FROM MID STREAM URINE SAMPLES
}

\author{
Nisha Regmi ${ }^{1, *}$, Sonali Kafle ${ }^{2}$, Rabin Paudyal ${ }^{3}$ \\ ${ }^{1,3}$ Department of Microbiology, Kathmandu College of Science and Technology, Kathmandu \\ ${ }^{2}$ Department of Microbiology, Bharosa Hospital, Kathmandu, Nepal \\ *Corresponding author: regminisha5@gmail.com
}

(Received: August 14, 2018; Revised: December 1, 2018; Accepted: December 4, 2018)

\begin{abstract}
A frequent and consistent evaluation of the prevalence, etiologic agents and predisposing factors of urinary tract infection (UTI) is necessary in developing country like Nepal to reduce its severe consequences. A regular and routine monitoring of multidrug resistant (MDR) clinical isolates is essential in laboratory practice. Five hundred and ninety one mid stream urine samples were collected from Bharosa Hospital of Kathmandu and a semi-quantitative method was used to determine the frequency of MDR uropathogens in the urine samples. Isolation, identification and antimicrobial susceptibility of isolated bacteria were done by standard microbiological procedure. From the total samples, 161 samples were found to be positive for UTI $(27.24 \%)$. Among these bacterial isolates, $57.14 \%$ were found to be MDR Nitrofurantoin, amikacin and ceftriaxone were found to be the most effective antibiotics against uropathogens
\end{abstract}

Keywords: Urinary tract infection, Multidrug resistance, Uropathogens, Antimicrobial Susceptibility Test, Midstream urine

\section{INTRODUCTION}

Urinary tract infection (UTI) is a spectrum of disease caused by microbial invasion of genitourinary tract that extends from the renal cortex of kidney to the urethral meatus. UTIs are among the most frequent infectious diseases affecting humans and represent an important public health problem with a substantial economic burden. In the USA, every year more than 7 million people with UTI come to visit physician and $15 \%$ of them use prescribed antibiotic (Bonkat et al. 2017). It was reported that UTI positive rate in Nepalese patient attending general hospital range from $23.1 \%$ to $37.4 \%$ (Rai et al. 2001). Nepal has about $61.4 \%$ people illiterate, who do not have concept of hygiene and thus are vulnerable to infections. In many parts of Nepal, the facilities for urine culture and antimicrobial susceptibility testing are not available leading to incorrect diagnosis of UTI. Antibiotics are usually given empirically before the laboratory results of urine culture are available. To ensure appropriate therapy, current knowledge of the organisms that cause UTI and their antibiotic susceptibility is mandatory (Chakraborty 2001).

The problem of antimicrobial resistance may be due to the fact that antibiotics are easily assessable without medical authorization or supervision in developing countries (Pokharel et al. 2006). This situation has led to inappropriate usage of antibiotics with patients taking the drugs for insufficient length of time or at sub optimal dosages, which may result in antimicrobial resistance. The antimicrobial resistance is a serious emerging problem throughout the world. Multiple drug resistant (MDR) bacterial isolates have been frequently reported from different parts of the world as an emergence of treatment problem. Antibiotic susceptibility profile and reporting of drug resistant strain would provide information for the appropriate antibiotic therapy. So, this study was intended to address hospital acquired bacterial isolates causing UTI. The result of this study will also help clinicians to facilitate the empirical treatment of patients with symptoms of UTIs. Moreover, the data would also help relevant authorities to formulate antibiotic prescription policies.

\section{MATERIALS AND METHODS}

A prospective cross-sectional study was carried out in diagnostic laboratory of microbiology in a hospital from October 2015 to March 2016. During this period, a total of 591 urine samples from patients suspected of UTI were collected and were processed according to the standard laboratory methods (Cheesbrough 2006). Urine culture was performed in MacConkey agar and blood agar to detect the presence of significant bacteriuria. Diagnosis of UTI was proceeded when at least $10^{5}$ organisms were present per $\mathrm{mL}$ of urine samples. Identification was done using morphological, cultural and biochemical tests as described by Vandepitte et al. (2003) and details of the processes are shown in the flowchart below (scheme 1).

Antibiotic susceptibility testing (AST) of bacterial isolates was done by Kirby-Bauer disc diffusion method following CLSI guidelines. The antibiotic discs used for this study were amikacin $(30 \mu \mathrm{g})$, cefalexin $(30 \mu \mathrm{g})$, cefixime $(5 \mu \mathrm{g})$, ceftriaxone $(30 \mu \mathrm{g})$, ciprofloxacin $(5 \mu \mathrm{g})$, cotrimoxazole (25 $\mu \mathrm{g})$, gentamicin $(10 \mu \mathrm{g})$, levofloxacin $(10 \mu \mathrm{g})$, nitrofurantoin $(300 \mu \mathrm{g})$ and ofloxacin $(5 \mu \mathrm{g})$. 


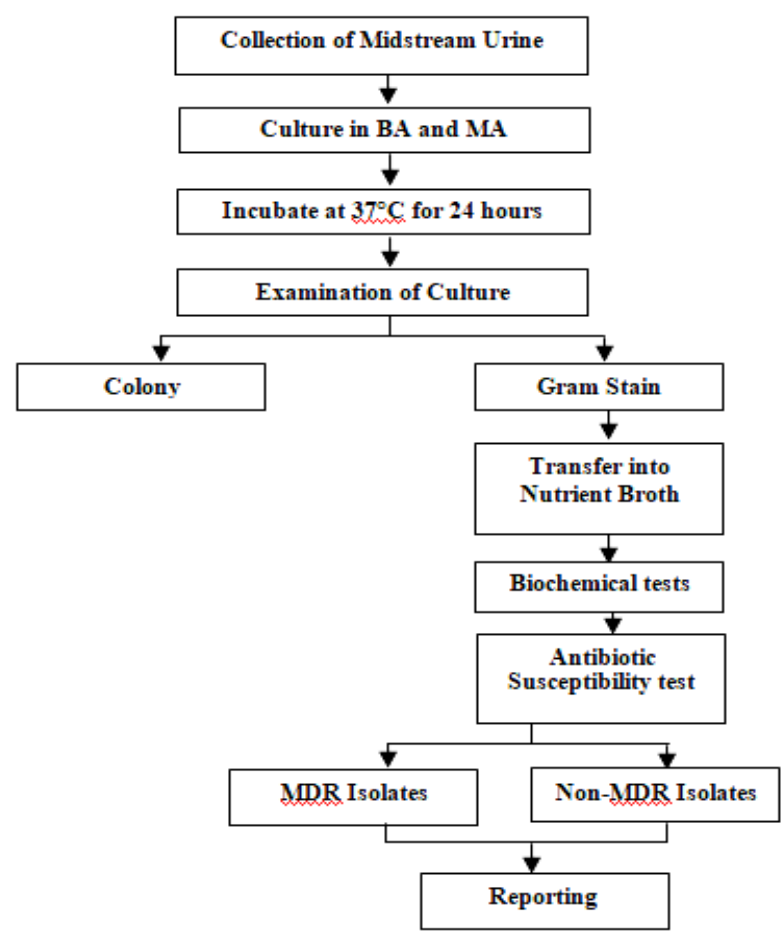

Scheme 1. Flowchart for processing of the clinical specimens

\section{RESULTS}

Out of 591 mid stream urine samples, 161 (27.24\%) samples showed significant growth whereas majority of the samples $430(72.76 \%)$ showed non-significant growth (Table 1). In this study, the age of the patient ranged between 18 months to 93 years. Among the 161 significant positive cultures, highest percent $38(23.75 \%)$ of significant growth culture was obtained from patients of age group between 21-30 years that was followed by age group 41-50 years $22(13.66 \%)$ as depicted in Table 2. A total of 9 species of bacteria belonging to seven different genera were isolated from significant bacteriuria urine samples, which are shown in Table 3. Among the isolates Escherichia coli $(65.84 \%)$ was found to be the most predominant organism followed by Klebsiella pneumoniae (12.42\%).

Table 1. Number of midstream urine samples and growth of bacterial isolates

\begin{tabular}{|l|c|c|}
\hline \multirow{2}{*}{ Growth Pattern } & \multicolumn{2}{|c|}{ Urine Samples } \\
\cline { 2 - 3 } & No. & $\%$ \\
\hline Significant growth & 161 & 27.24 \\
\hline Non-significant growth & 430 & 72.76 \\
\hline Total & $\mathbf{5 9 1}$ & $\mathbf{1 0 0}$ \\
\hline
\end{tabular}

E.coli was found to be most sensitive to nitrofurantoin 71 $(66.98 \%)$, followed by ceftriaxone $69(65.09 \%)$ and resistant to cotrimoxazole $48(45.28 \%)$ and cefalexin 27
(25.47\%). Klebsiella sps was found to be sensitive to amikacin $15(75 \%)$ followed by ceftriaxone and resistant to ofloxacin $10(50 \%)$ (Table 4). Among the isolated organisms, $92(57.14 \%)$ were found to be MDR. E.coli was the most prevalent isolate that is $58(63.04 \%)$ (Table 5).

Table 2. Sex-wise and age-wise distribution of the isolates

\begin{tabular}{|c|c|c|c|c|c|c|}
\hline \multirow{2}{*}{$\begin{array}{c}\text { Age } \\
\text { Group } \\
\text { (years) }\end{array}$} & \multicolumn{2}{|c|}{ Male } & \multicolumn{2}{|c|}{ Female } & \multirow[b]{2}{*}{$\begin{array}{c}\text { Total } \\
\text { No. }\end{array}$} & \multirow[b]{2}{*}{$\%$} \\
\hline & No. & $\%$ & No. & $\%$ & & \\
\hline $0-10$ & 1 & 16.67 & 5 & 83.33 & 6 & 3.7 \\
\hline $11-20$ & 2 & 22.22 & 7 & 77.78 & 9 & 5.6 \\
\hline $21-30$ & 2 & 5.26 & 36 & 94.74 & 38 & 23.6 \\
\hline $31-40$ & 2 & 10.0 & 18 & 90.00 & 20 & 12.4 \\
\hline $41-50$ & 6 & 27.27 & 16 & 72.73 & 22 & 13.7 \\
\hline $51-60$ & 10 & 47.62 & 11 & 52.40 & 21 & 13.1 \\
\hline $61-70$ & 2 & 15.38 & 11 & 84.62 & 13 & 8.1 \\
\hline $71-80$ & 5 & 27.78 & 13 & 72.22 & 18 & 11.2 \\
\hline $81-90$ & 3 & 30.0 & 7 & 70.00 & 10 & 6.2 \\
\hline $91-100$ & 2 & 50.0 & 2 & 50.00 & 4 & 2.4 \\
\hline Total & 35 & & 126 & & 161 & 100 \\
\hline
\end{tabular}

Table 3. Distribution pattern of different uropathogens isolated from urine samples

\begin{tabular}{|l|c|c|}
\hline Bacteria & Frequency & $\%$ \\
\hline E.coli & 106 & 65.8 \\
\hline Klebsiella pneumoniae & 14 & 8.7 \\
\hline Klebsiella oxytoca & 6 & 3.7 \\
\hline Enterococcus & 16 & 10 \\
\hline Enterobacter & 13 & 8.1 \\
\hline Pseudomonas aeruginosa & 3 & 1.9 \\
\hline Staphylococcus aureus & 1 & 0.6 \\
\hline Staphylococcus saprophyticus & 1 & 0.6 \\
\hline Proteus vulgaris & 1 & 0.6 \\
\hline Total & $\mathbf{1 6 1}$ & $\mathbf{1 0 0}$ \\
\hline
\end{tabular}

Table 4. Antibiotic susceptibility pattern of $E$. coli $(\mathrm{n}=106)$ and Klebsiella spp $(\mathrm{n}=20)$

\begin{tabular}{|l|c|c|c|c|}
\hline \multirow{2}{*}{ Antibiotics } & \multicolumn{2}{|c|}{ E. coli } & \multicolumn{2}{c|}{ Klebsiella spp } \\
\cline { 2 - 5 } & $\begin{array}{c}\text { Susceptible } \\
\text { No. }\end{array}$ & $\%$ & $\begin{array}{c}\text { Susceptible } \\
\text { No. }\end{array}$ & $\%$ \\
\hline Amikacin & 68 & 64 & 15 & 75 \\
\hline Cefalexin & 16 & 15 & 3 & 15 \\
\hline Cefixime & 49 & 46 & 9 & 45 \\
\hline Ceftriaxone & 69 & 65 & 12 & 60 \\
\hline Ciprofloxacin & 40 & 38 & 12 & 60 \\
\hline Cotrimoxazole & 48 & 45 & 10 & 50 \\
\hline Gentamicin & 62 & 59 & 7 & 35 \\
\hline Levofloxacin & 50 & 47 & 5 & 25 \\
\hline Nitrofurantoin & 71 & 67 & 10 & 50 \\
\hline Ofloxacin & 30 & 28 & 4 & 20 \\
\hline
\end{tabular}


Table 5. MDR patterns of isolated organisms

\begin{tabular}{|l|c|c|c|}
\hline \multicolumn{1}{|c|}{ Organisms } & $\begin{array}{c}\text { Total } \\
\text { isolates }\end{array}$ & $\begin{array}{c}\text { MDR } \\
\text { No. }\end{array}$ & $\%$ \\
\hline E coli & 106 & 58 & 63.04 \\
\hline Klebsiella pneumoniae & 14 & 13 & 14.13 \\
\hline Klebsiella oxytoca & 6 & 3 & 3.30 \\
\hline Enterococcus & 16 & 8 & 8.70 \\
\hline Enterobacter & 13 & 7 & 7.53 \\
\hline Pseudomonas aeruginosa & 6 & 3 & 3.30 \\
\hline Total & $\mathbf{1 6 1}$ & $\mathbf{9 2}$ & $\mathbf{1 0 0}$ \\
\hline
\end{tabular}

\section{DISCUSSION}

In this study, prevalence of UTI was found to be $27.24 \%$ which is relatively lower than reported in the study of Mishra et al. (2005) and Shrestha et al. (2005). This might be due to patients taking antibiotics prior to urine culture or infection due to slow growing organisms or fastidious organisms. Out of 161 UTI positive cases, infection was found to be higher in female compared to male. In addition, high infection rate was found in age group of 2130 year as compared to other age groups $(\mathrm{p}<0.05)$. Out of 126 female patients, showing significant growth of urine culture, $36(94.74 \%)$ female patients were from this age group. In young women, sexual activity is the cause of $75-90 \%$ of bladder infections, with the risk of infection related to the frequency of sex (Nicole 2001). A urinary tract infection is of concern in pregnancy due to increased risk of kidney infections (Dielubanza et al 2011). Sexual activity is an important factor in the pathogenesis of UTI in female.

In this study, $92(57.5 \%)$ were MDR; it means they were resistant to two or more than two different structural classes of antibiotics. Present finding is in consistence with the study done by Baral (2008), Pokharel (2006), Poudyal (2011) and Shrestha et al. (2005) which showed $47.94 \%, 39.69 \%, 60.40 \%, 64.6 \%$ and $55.87 \%$ MDR isolates, respectively. In a study by Bomjan (2005), the highest proportion $(68.33 \%)$ of MDR among urinary isolates was reported. The consistent and high-level susceptibility of $E$. coli to nitrofurantoin may be influenced by nitrofurantoin's narrow spectrum of activity, limited indication (treatment of acute cystitis), narrow tissue distribution (low or undetectable serum concentrations) and limited contact with bacteria outside the urinary tract (Jones et al. 1999). In a study done by Kurutepe et al. (2005), $100 \%$ of MDR E coli isolates were resistant to ampicillin whereas $80.6 \%, 74.1 \%$ and $33.3 \%$ of them were resistant to ciprofloxacin, gentamicin, nitrofurantoin, respectively. High resistance rate of MDR $E$ coli isolates to norfloxacin found in the present study is a great concern. A gradual decrease in the susceptibility of $E$. coli to fluoroquinolones (approximately $1 \%$ per annum) has also been reported by the US arm of the SENTRY surveillance program, with no change in susceptibility to nitrofurantoin (Jones et al.
1999, Mathai et al. 2001). Increasing fluoroquinolones resistance among urinary $E$. coli has also been documented in studies conducted outside the US (Goettsch et al. 2000). The increasing prevalence of MDR Enterobacteriaceae limits available treatment options for infections caused by these organisms. Due to the lack of new antibiotics, there is a valid rationale for testing older antibiotics that retain some activity against MDR bacteria.

\section{CONCLUSION}

This study showed that E.coli $106(65.83 \%)$ was the major organism in UTI followed by Klebsiella pneumoniae $(12.42 \%)$. Majority $(57.14 \%)$ of the isolates included in this study was found resistant to two or more antibiotics (MDR). E. coli was found to be the most predominant MDR isolates followed by Klebsiella pneumoniae. Moreover, this study concluded that all $E$. coli isolates and most of other Gram-negative bacteria isolates were sensitive to amikacin, ceftriaxone and nitrofurantoin so they can be used as a drug of choice for the treatment of UTI. Similarly, Gram positive bacteria were found the most sensitive to nitrofurantoin. Hence, nitrofurantoin can be the best choice of antibiotics for UTI.

\section{ACKNOWLEDGEMENT}

Authors are deeply indebted to Mr. Kamal Pandey for providing of laboratory facilities.

\section{REFERENCES}

Baral, P. 2008. Multidrug resistance among various clinical bacterial isolates and productions of different types of $\beta$-lactamase with subsequent transfer mechanism by plasmid DNA analysis. M. Sc. Dissertation, Central Department of Microbiology, Tribhuvan University, Kathmandu, Nepal.

Bomjan, R. 2005. Prevalence of multidrug resistant strains with reference to extended-spectrum $\beta$ lactamase producing strains among the bacterial pathogens isolated from different clinical samples at Tribhuvan University Teaching Hospital. M. Sc. Dissertation, Central Department of Microbiology, Tribhuvan University, Kathmandu, Nepal.

Bonkat, G., Pickard, R., Bartoletti, R., Bruyere, F., Cai, T. and Geerlings, S.E. 2017. Guidelines on urological infections. EAU.

Chakraborty, P. 2001. A textbook of microbiology. $2^{\text {nd }} \mathrm{ed}$., New Central book Agency (P.) Ltd., Calcutta, pp. 112-120.

Chessbrough, M. 2006. District laboratory practice in tropical countries (Part 2). Cambridge University Press, pp. 105-115. 
Dielubanza, E.J. and Schaeffer, A.J. 2011. Urinary tract infection in women. The Medical Clinics of North America 95(1): 27-41.

Goettsch, W., van Pelt, W., Nagelkerke, N., Handrix, M.G., Buiting, A.G., Petit, P.L., Sabbe, L.J., van Griethysen, A.J. and de Neeling, A.J. 2000. Increasing resistance to fluoroquinolones in Escherichia coli from urinary tract infections in Netherlands. Journal of Antimicrobial Chemotherapy 46(2): 223-228.

Jones, R.N., Kugler, K.C., Pfaller, M.A. and Winokur, P.L. 1999. Characteristics of pathogens causing urinary tract infections in hospitals in North America: results from the SENTRY antimicrobial surveillance program, $1997 . \quad$ Diagnostic Microbiology and Infectious Disease 35(1): 55-63.

Kurutepe, S., Surucuoglu, S., Sezgin, C., Gazi, H., Gulay, M. and Ozbakkaloglu, M. 2005. Increasing antimicrobial resistance in Escherichia coli isolates from community- acquired urinary tract infections during 1998-2003 in Manisa, Turkey. Japanese Journal of Infectious Diseases 58(3): 159-161.

Mathai, D., Jones, R.N., Pfaller, M.A. and the SENTRY Participant Group North America 2001. Epidemiology and frequency of resistance among pathogens causing urinary tract infections in 1510 hospitalized patients: a report from the SENTRY antimicrobial surveillance program (North America). Diagnostic Microbiology and Infectious Disease 40: 129-136.

Mishra, S.K., Koirala, J., Dahal, R.K. and Pokhrel, B.M. 2005. Status of multidrug resistance and extended spectrum $\beta$-Lectamase producing strains causing lower respiratory tract and urinary tract infection among patients attending TUTH. Journal of Nepal
Association for Medical Laboratory Science 7: 3032.

Nicole, L.E. 2001. Epidemiology of urinary tract infections. Journal of Infection Medicine 18: 153162.

Pokharel, B.M., Koirala, J., Mishra, S.K., Dahal, R.K., Khadga, P. and Tuladhar, N.R. 2006. Multi drug resistance and extended spectrum beta lactamase producing strains causing lower respiratory tract and urinary tract infections. Journal of Institute of Medicine 28(3): 19-27.

Poudyal, S., Bhatta, D.R., Shakya, G., Upadhaya, B., Dumre, S.P., Buda, G. and Kandel, B.P. 2011. Extended spectrum $\beta$ - lactamase producing multidrug resistant clinical bacterial isolates at National Public Health Laboratory, Nepal. Nepal Medical College Journal 13(1): 34-38.

Rai, C.K., Pokhrel, B.M. and Sharma, A.P. 2001. A prospective study on antibiotic sensitivity profile of the organisms associated with clinical infections among the patients attending TUTH. Journal of Nepal Association for Medical Laboratory Science 3: 13-16.

Shrestha, B., Basnet, B.R. and Shrestha, P. 2005. Prevalence of Urinary tract infection in female patients in attending Kathmandu Model Hospital. Journal of Nepal Association for Medical Laboratory Science 7: 10-12.

Vandepitte, J., Verhaegen, J., Engbaek, K., Rohner, P., Piot, P. and Heuck, C.C. 2003. Basic laboratory procedures in clinical bacteriology, WHO. ISBN 924154545 